\title{
Using Skin Conductance and Facial Electromyography to Measure Emotional Responses to Tourism Advertising
}

\author{
Abstract: Although an objective and increasingly common technique in marketing, \\ media and psychology, psycho-physiological measures are rarely used in tourism \\ research to detect tourism consumers' spontaneous emotional responses. This study \\ examines the use of psycho-physiological measures in tourism and in particular explores \\ the usefulness of skin conductance and facial electromyography methods in tracking \\ emotional responses to destination advertisements. Thirty-three participants were \\ exposed to three destination advertisements while their self-report ratings, real-time skin
} conductance and facial electromyography data as well as post hoc interview data were obtained. The results demonstrate that, compared with self-report measures, psychophysiological measures are able to better distinguish between different destination advertisements, and between different dimensions of emotion. Participants' affective experience reported in post hoc interviews was found to be consistent with emotional peaks identified from continuous facial electromyography and skin conductance monitoring. These results validate the ability of psychophysiological techniques to capture moment-to-moment emotional responses and it is concluded that psycho-physiological methods are useful in measuring emotional responses to tourism advertising. Methodological insights regarding the constraints associated with the use and application of psychophysiological methods are discussed.

Key words: tourism advertising; emotional responses; skin conductance, facial 
electromyography, real-time response measurement 


\section{Introduction}

Evoking emotional responses is an important strategy to engage consumers with advertisements (Bardzell, Bardzell, \& Pace, 2009; Peacock, Purvis, \& Hazlett, 2011; Teixeira \& Wedel, 2012). Tourism promotional campaigns often use emotion appeals and aim to evoke consumers' feelings by emphasizing the unique characteristics and personalities of the tourism products (Kandampully, Mok, \& Sparks, 2001). Unlike advertisements for tangible products that are mainly based on utility and instrumentality, tourism advertising is usually image-laden and aims to evoke mental imagery (Kim, Kim, \& Bolls, 2014). This is based on the fact that potential tourists are not able to experience their holiday beforehand, and their buying decisions are largely influenced by their mental images of a destination's offerings and associated emotional responses (Morgan \& Pritchard, 2000; Walters \& Sparks, 2012).

In the wider literature of advertising effectiveness, there is significant discussion of the positive influence of emotional responses on post-exposure attitude and recall (Holbrook \& Batra, 1987; Morris, Woo, Geason, \& Kim, 2002). There is increasing emphasis on the value-expressive components of commercials, indicating the importance of emotional response in evaluating an advertisement’s effectiveness (Hazlett \& Hazlett, 1999). Research on the direct effect of advertising allows advertisers to improve their advertisement performance based on an evaluation of viewers' psychological processes. However, it is surprising that little research has been conducted to understand the mental processing involved in consumers' responses to tourism campaigns, especially their emotional responses. Kim et al. (2014) indicate that most tourism advertising studies have examined the post-exposure effects rather than mental processing during exposure-the internal mechanism that generates these resulting effects. Consequently, there is no research basis to determine why potential tourists have certain attitudes to various advertisements. 
A review of previous research examining tourism advertising effectiveness reveals a dependence on the self-report method. This method requires respondents to report their cognitive or affective responses to an advertisement by completing a questionnaire. While popular, simple and inexpensive, the reliability and validity of self-report methods have been increasingly challenged, especially when used for measuring emotional responses. First, emotion is usually measured after the advertisement has been displayed to viewers rather than while it is being presented (Poels \& Dewitte, 2006). Relying on memory to recall emotions may introduce cognitive biases and socially desirable responses (Paulhus, 2002). Second, emotion can occur unconsciously or in the absence of conscious awareness of the stimuli. Consumers may be unaware that they have gone through a series of subliminally triggered emotional reactions that drive judgement and further behaviors (Winkielman \& Berridge, 2004). Thus, self-report measures may exclude important information because an individual is unable to report their unconscious emotional responses. Importantly, the self-report method is incapable of capturing consumers' emotional responses in real time, especially when an audience is exposed to continuous stimuli such as audio or video.

In other disciplines such as psychology, marketing and media, scholars have sought to overcome the criticisms of self-report measures of emotions by using alternative approaches. In particular, psychophysiological measures have been used to provide a more objective and unbiased method to measure individuals’ emotional responses (Li, Scott, \& Walters, 2015). Algie (2005) notes that a discrepancy exists between what we think our responses to advertising messages are, and how we actually respond to the stimuli. Psychophysiological measures such as skin conductance and facial electromyography do not rely on memory and cognitive processing, and enable researchers to gather data that is beyond an individual's conscious control. More importantly, psychophysiological methods are capable of tracking individuals' moment-to-moment emotional responses, which allows the researchers to visualize respondents’ emotional flow patterns across time. 
Evaluation of the effectiveness of tourism advertisements requires understanding how tourism consumers mentally respond to such stimuli, especially their unconscious emotional responses evoked during the process. This is supported by research indicating that most viewers' affective reactions to advertising stimuli register mainly in the regions of brain unrelated with conscious thinking (Ambler, Ioannides, \& Rose, 2000). For continuous stimuli such as those seen in broadcast media, an approach that is able to examine a destination advertisement's moment-to-moment performance is needed. In this methodological paper, we adopt the dimensional approach to describing emotion (see details in literature review) and argue that emotional responses can be plotted onto a two-dimensional space with pleasure and arousal as the coordinate axes. Based on the criticisms of self-report measures and the increasing use of psychophysiological methods in other disciplines, this study will investigate how this method can be applied to tourism. Specifically, this paper will explore the usefulness and capabilities of facial EMG and skin conductance as real-time and precise techniques for detecting individuals' emotional responses to destination advertisements. 


\section{Literature review}

\section{Tourism advertising effectiveness}

In order to maximize market share, local and national tourism agencies invest significantly in mass media advertising (Ruhanen, McLennan, \& Moyle, 2013). This investment in turn has led to increased emphasis on effective evaluation techniques. According to Scott, Green, and Fairley (2015), two main approaches are currently used to evaluate tourism advertising effectiveness before and after the advertisement is launched in market. The first approach entails the measurement of destination awareness, visitation, and visitor expenditure after the targeted audience has been exposed to the advertising material. This approach involves several specific techniques such as the level of customer enquiries (also known as conversion studies) (Pratt, McCabe, Cortes-Jimenez, \& Blake, 2010), the use of advertising tracking models (Spencer, 2013) and buyer-purchase approach (Butterfield, Deal, \& Kubursi, 1998). A review of these techniques has been conducted by Kim, Hwang, and Fesenmaier (2005). The major limitation of this approach lies in the fact that the effectiveness of the advertisements cannot be evaluated before they are launched (Scott, Green, and Fairley, 2015).

An alternative 'diagnostic approach' is based on evaluation of advertising materials prior to their use in the market (Scott, Green, \& Fairley, 2016). This approach usually utilizes experimental design methods to explore the most effective stimuli or the most effective combination of stimuli in the advertisement. In particular, the effect of particular copy elements such as an endorser (Van der Veen \& Song, 2014), images of tour leaders (Wang, Hsieh, \& Chen, 2002), experiential texts (Goossens, 1995), pictorial and textual stimuli (Walters, Sparks, \& Herington, 2007) and gender of the endorser (Luoh \& Lo, 2012) have been studied by tourism researchers. Among these studies, attitude towards the advertisement (Aad), attitude towards the brand (Abr), or purchase intention (PI) are employed as measures of advertising 
effectiveness, and essentially researchers focus on how the manipulation of particular advertising stimuli influences advertising effectiveness. The main limitation of this approach is that it relies on the potential tourist's attitude or purchase intention, rather than actual behavior.

Neither of the above methods is sufficient to provide a comprehensive understanding of how destination advertising affects tourism consumers. Consumers' mental processing of the destination advertising is treated as a 'black box' mediating between consumers' exposure to stimuli and their attitude development, and has rarely been explored. The wider literature on advertising effectiveness emphasizes the importance of emotional responses in consumers' mental processing of advertising messages. A large number of studies have indicated that emotion acts an important precursor of other consumer responses such as attitudes towards the advertisement and brand (Holbrook \& Batra, 1987), brand interest (Morris et al., 2002), and purchasing intention (Morris et al., 2002). Morris et al (2002) claim that an emotional response may in fact be a more reliable indicator of advertising effectiveness than cognition when the featured products or services are hedonic in nature (Sirgy, 1991). However, little effort has been undertaken in tourism advertising studies to understand consumers' emotional responses provoked by destination advertisements. Walters and Sparks (2012) found the emotional responses evoked by concrete imagery presented in tourism advertising to be positively related with product interest and purchasing decisions. However, emotion in their study was measured using a self-report method.

\section{Approaches to the study of emotion}

Two frameworks are commonly used within tourism to describe emotion: the basic emotion approach and the dimensional approach (Li et al., 2015). Supporters of the basic emotion approach adovocate that a finite set of basic emotions exist, such as joy, fear and anger. These basic emotions are innate to all human beings and are present from birth (Plutchik, 1982). For example, Plutchik (1980) proposed eight different 
primary emotions (i.e., surprise, expectancy, disgust, acceptance, sadness, joy, anger and fear) and posited that secondary emotions are the derivative of primary emotions or result from a combination of basic emotions. Instead of labelling different basic emotions, the dimensional approach distinguishes emotions though the identification of a set of fundamental affective dimensions. Pleasure-arousal-dominance (P-AD) is the most common theory within the dimensional framework (Russell \& Mehrabian, 1974), and it has been widely used in tourism research. Pleasure refers to the hedonic quality of an affective state whereas the arousal dimension refers to the bodily activation ranging from calm or sleepy to highly excited or energized. The dominance dimension refers to whether the individual is able to control the emotion or not. However, in Russel's later research, the dimension of dominance was deleted from the model as dominance requires cognitive processing and for this reason was deemed not applicable to the measuerment of emotional responses (Russell \& Pratt, 1980).

The dimensional approach is considered more parsimonious compared with the basic emotional approach (Mauss \& Robinson, 2009) given its ability to cover the full spectrum of human emotions. Huang (2001) considers that emotion within consumer behaviour is short lived and hardly ever seen in its pure form, and it is questionable to label emotion with a fixed name, as advocated by the basic emotion approach. Given its simple and intuitive nature, the dimensional approach is more commonly adopted than the basic emotion approach in consumer research (Huang, 2001).

\section{Self-report methods and psychophysiological measures}

Tourism researchers with an interest in advertising effectiveness have until recently relied on self-report measures to understand consumers' responses such as top-of-mind awareness (Kim et al., 2005), attitudes towards the advertisement (Luoh \& Lo, 2012), or emotional responses evoked by concrete imagery presented in tourism advertising (Walters \& Sparks, 2012). For example, after viewing an advertisement, 
tourism consumers may be asked to rate the extent to which they were feeling particular emotions (e.g., "I felt a sense of pleasure”) using a 7-point Likert-type scale where $1=$ not at all to $7=$ very much. Selfreport methods are convenient and easy to use, and enable researchers to collect large respondent samples (Bagozzi, Gopinath, \& Nyer, 1999). Self-report measures of emotion, however, have several limitations in their reliability and validity.

First, emotions can be conscious or unconscious. According to Poels and Dewitte (2006), advertisement processing is usually unconscious and individuals may not be mindful of their psychophysiological responses. This is consistent with the early research on emotion by Zajonc (1980) who argued that emotion can be evoked with little deliberation or even without cognition. Evidence from neuroscience research also confirms that individuals can experience emotions without being consciously aware of them (Ambler et al., 2000). Neuroscientists have revealed that at times emotions communicate directly with the sense organs and by-pass the cerebral cortex, resulting in individuals not consciously recognising that they are having an emotional response (LeDoux, 1998). Thus, self-report measures of emotion may result in the omission of valuable emotion-related information. In particular, a lack of emotional response reported by the respondent may mislead the researcher when drawing conclusions about the effectiveness of a marketing campaign as they fail to account for the unconscious emotional responses that could well influence individual behaviours and values (Winkielman, Berridge, \& Wilbarger, 2005).

Second, self-reported emotions may be distorted and non-representative of the respondent's actual emotional response to the stimuli in question. Respondents using a self-report emotions scale are usually asked to recall their emotions after they have been exposed to the stimulus, and thus reliance on memory may influence the emotions reported due to individuals’ capacity to remember (Robinson, Robinson, \& Clore, 2002). Further, rationally worded questions tend to elicit rational responses (LaBarbera \& Tucciarone, 1995, p. 34). Self-report measures describe the respondent's perception of their emotions, 
which can be seen as a form of cognitive appraisal. In addition, respondents may not report their real emotional responses to sensitive topics due to a social desirability bias (Paulhus, 2002).

Third, self-report questionnaires cannot record respondents’ moment-to-moment emotional responses and are unable to detect the emotional peaks and troughs that may occur particularly when viewing and responding to video footage as opposed to still images. It is important to acknowledge that emotion seldom occurs at one point in time (Scherer, 2009), and its measurement therefore requires advanced methodological techniques to monitor the changes that occur over the course of the stimulus exposure. When using self-report measures, respondents are typically asked to recall their overall feelings in relation to a particular event or advertising stimulus, and this may not capture subtle emotional changes across the entire experience. Maier (2009) considers it is difficult to know using a questionnaire which elements, arguments or events embedded in a continuous stimulus lead respondents to feel emotions.

Psychophysiology is a term used to describe the investigation of external physiological variations that result from internal psychological activites (Cacioppo, Tassinary, \& Berntson, 2007), and represents a plausible alternative for the measurement of emotion in the study of consumer behaviour. Compared with self-report methods, psychophysiological measures are not influenced by socially desirable responses (Paulhus, 2002). Morever, psychophysiological methods are capable of detecting emotional responses that respondents are not consciously aware of (Ravaja, 2004). Continuous measures of physiological reactions can be used to examine the entire emotional flow pattern without distraction, and this can provide valuable data points for detailed analysis and comparison. The current study adopts facial electromyography and skin conductance to provide separate measures of pleasure and arousal, and explores the capabilities of these two techniques in detecting emotional responses to tourism advertising. 
and is capable of detecting facial muscle contractions in response to weakly evocative affective stimuli even though no overt facial expressions are noticed (Tassinary, Cacioppo, \& Vanman, 2007). Facial expression can reflect valuable emotion-associated information (Partala, Surakka, \& Vanhala, 2006). Previous studies have found that the signals from the zygomatic major muscles that are activated when smiling are positively related with positive emotions, while negative emotions will trigger the activation of the corrugator supercilli muscles (activated when frowning) (Tassinary et al., 2007).

Skin conductance (SC), also known as 'electrodermal activity (EDA)', is an important index of respondents' arousal levels and is measured in microsiemens. When individuals are exposed to an exciting stimulus, their sympathetic nervous system will be activated and correspondingly their sweat gland activities will increase, which in turn results in stronger skin conductivity (Grabe, Lang, Zhou, \& Bolls, 2000). Phasic and tonic skin conductance are two types of data collected by the skin conductance measurement technology. Phasic data refers to respondents’ skin conductance responses (SCR), which usually last for only a few seconds, and is evoked by a particular stimulus or event. Tonic data, on the other hand, also termed skin conductance level (SCL), refers to respondents' longer-term reactions to stimuli and usually lasts for at least 30 seconds (Algie, 2005).

A number of studies of consumer emotions in marketing and media have adopted these two psychophysiological measures, and found them effective in recording consumers’ affective responses to a service experience and marketing stimulus (Li et al., 2015). Bolls, Lang, and Potter (2001) demonstrated that facial EMG is a valid measure to evaluate the valence of affective responses to radio messages and asserted that facial EMG is particularly useful when the participants are exposed to media stimuli related to sensitive topics. They also used skin conductance to measure arousal and found that participants have more spontaneous skin conductance responses during positive radio advertisements in comparison with negative radio advertisements. Hazlett and Hazlett (1999) established that facial EMG is 
more strongly related to respondents’ recall levels than self-report measures. A review of psychophysiological measures in marketing was conducted by Wang and Minor (2008). Despite their increasing use in marketing research, psycho-physiological measures are still new to tourism research, which relies heavily on traditional self-report questionnaires.

The goal of this methodological study is to explore the use and capabilities of facial EMG and SC in measuring consumers' emotional responses to destination advertisements. This objective will be achieved by comparing this innovative approach with a traditional self-report measure, represented by the SelfAssessment Manikin [SAM] (Lang, 1980). In particular, the following two research questions (RQ) will be addressed.

RQ1: Are psycho-physiological methods more useful and effective than self-report methods in measuring individuals’ overall emotional responses to destination advertisements?

To answer this question, we firstly compare individuals' overall emotional responses to destination advertisements, measured by both self-report scales and psychophysiological methods. In particular, we assess the capabilities of self-report and psychophysiological methods in differentiating emotional appeals from non-emotional appeals as well as their efficacies in discriminating between similar emotional appeals. This study adopts the dimensional approach that conceptualizes emotion as having two dimensions, pleasure and arousal. A large number of studies have posited that pleasure and arousal are independent of one another (e.g., Barrett \& Russell, 1999; Russell, 1980). Kuppens, Tuerlinckx, Russell, and Barrett (2013, p. 919), wrote 'how pleasant one is feeling gives no information about how activated one is feeling and vice versa'. Therefore, we will also evaluate the ability of both self-report and psychophysiological methods to distinguish these two fundamental dimensions of emotion. 
RQ2: Are psycho-physiological measures valid techniques to record individuals’ moment-to-moment emotional responses?

Psycho-physiological measures are not only able to reflect individuals’ overall emotional responses, but are also able to record dynamic emotional responses over the course of the stimulus exposure, especially those peak moments where individuals have strong feelings. To illustrate the potential of real-time facial EMG and SC data and validate the peaks that occur in the physiological waveforms, we average participants' real-time facial EMG and SC data and identify the significant peaks. Those peak moments are then compared with participants’ affective experience reported in the follow-up interviews. 


\section{Method}

This study involves a multi-measurement method including a self-report questionnaire, psychophysiological measures of emotion and post treatment interviews.

\section{Stimuli selection}

Destination promotional videos (DPV) released by official destination marketing organizations (DMOs) were used as the stimuli in this study. The use of DMO advertisements served as a control for professional quality and realism. Six destination advertisements were selected from a pool of online advertisements using the following criteria:

1. Destination advertisements with emotional appeals were collected according to the definition of emotional appeal (Aaker \& Stayman, 1992; Sirgy, 1991) and various classifications of emotional appeals (Albers \& Stafford, 1999; Mueller, 1987; Pollay, 1983).

2. Advertisements with a duration less than 2 minutes were selected in order to reduce viewer fatigue.

3. Destination-based advertisements were sought in this study; therefore DPVs advertising a particular hotel, restaurant or attractions were excluded.

To confirm the presence of an emotional appeal within the six selected advertisements, the advertisements, along with a control advertisement comprising what the researcher considered was a rational account of a destination's features, were pre-tested with 41 undergraduate students. The seven destination advertisements were shown in random order and students were asked to rate their emotional response (i.e., pleasure and arousal levels) using the self-assessment manikin (SAM) measurement scale (Lang, 1980). SAM is a 5-character-scale that has been demonstrated to be a reliable and valid measure of emotional responses to media messages (Morris et al., 2002; Simons, Detenber, Roedema, \& Reiss, 
1999), This measurement technique also aligns with Mehrabian and Russel’s PAD-dimensions (1974), formerly discussed.

Mean pleasure and arousal levels for each advertisement were calculated. Two emotional advertisements were selected for use in the study. An advertisement focusing on Switzerland received the highest score in pleasure, and yielded significantly higher pleasure ratings $(M=4.17, S D=0.73)$ than arousal ratings $(M=3.09, S D=0.86) ; t(40)=7.369, p<.001$. An advertisement promoting Hamilton Island in Australia received the highest score in arousal, and yielded significantly higher arousal ratings $(M=4.21, S D=1.08)$ than pleasure ratings $(M=3.56, S D=1.02) ; t(40)=-4.258, p<.001$. The pre-test also confirmed that the control advertisement (Adelaide, Australia), which was treated as a non-emotional advertisement in this study, received the lowest score on both pleasure $(M=1.97)$ and arousal $(M=1.65)$ dimensions. The details of these three destination advertisements are shown in Table 1.

\section{TABLE 1 ABOUT HERE}

\section{Participants}

Thirty-eight university students and staff from an Australian university participated in this study. Participation was voluntary, and upon completion, each participant received a \$10 voucher for their participation. Of the original thirty-eight participants, data from two participants with excessive EMG baselines were not included in the analysis. Another three respondents were recognized as 'nonresponders (hypo-responsive)' (Braithwaite et al., 2013) in skin conductance and their data were discarded. Consequently, the data from thirty-three participants' responses were used in the analysis. Given the collection of physiological data is time consuming and complex, resulting in what can be an onerous task for participants, small samples are common in studies involving psychophysiological techniques and are not intended to be representative (Bolls et al., 2001; Micu \& Plummer, 2010; Ohme, Reykowska, Wiener, \& Choromanska, 2009; Partala et al., 2006; Ravaja \& Kallinen, 2005). 


\section{Apparatus}

The digital facial EMG and SC data were collected and analyzed using Biopac ${ }^{\mathrm{TM}}$ BioNomadix hardware

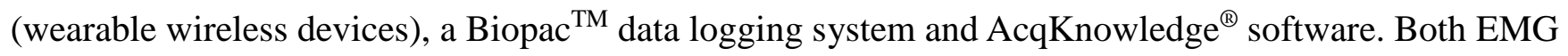
and SC data were collected with a sampling rate of $2000 \mathrm{~Hz}$. Specifically, skin conductance data were collected by attaching two standard snap electrodes to the index and middle fingertips of the nondominant hand of each participant. The electrode was connected with a lead $(30 \mathrm{~cm})$ attached to a wireless transmitter. The transmitter sends skin conductance signals to the receiver and the real time skin conductance data can be read via software (AcqKnowledge ${ }^{\circledR}$ ). In line with the latest published guidelines for analysis of SC data, the frequency and amplitude of skin conductance responses (SCR) were utilized as two indicators of phasic skin conductance data for continuous stimuli (e.g., audio or video) (Boucsein, 2012; Braithwaite, Watson, Jones, \& Rowe, 2013). The criterion for skin conductance response (SCR) was greater than $0.05 \mu \mathrm{S}$ (Braithwaite et al., 2013). To demonstrate the capability of the SC measure in capturing tourism consumers' real time emotional responses to advertisements, the tonic skin conductance level (SCL) was also used to indicate moment-to-moment arousal level.

Facial EMG data were collected by recording participants’ zygomatic major muscle activities. Firstly the recording sites on the participant's face were carefully located in accordance with published facial EMG guidelines (e.g., Fridlund \& Cacioppo, 1986). The participants were asked to cleanse the facial area with skin cleansing alcohol and an abrasive pad for the removal of non-conductive cells. Two reusable electrode snaps (4mm) filled with the electrode gel were applied to the zygomaticus major muscle. A ground electrode was also placed on the area behind the ear. The transmitter sends electrical potentials generated by muscle cells to the receiver and the moment-to-moment facial EMG data can be read via psychophysiological software (AcqKnowledge $^{\circledR}$ ) in the computer. Offline, the facial EMG data were filtered, digitally rectified, and integrated with a time constant of 50 samples (Philipp, Storrs, \& Vanman, 2012). Mean facial EMG score was used as the indicator of pleasure level in this study (Boxtel, 2001). 


\section{Self-report emotion measures}

Participants were required to complete a questionnaire indicating their subjective 'pleasure' and 'arousal' levels after watching each of the DPVs. Both 'pleasure' and 'arousal' were measured using the SelfAssessment Manikin [SAM] (Lang, 1980).

\section{Procedure}

Upon entering the research lab, the participants were provided with an introduction to the research study and relevant apparatus. Informed consent was obtained from all the participants. Participants were tested one at a time. They were asked to sit in a comfortable chair and watch three destination promotional videos on the center of a 23.8-inch monitor while their skin conductance and facial EMG responses were registered. To avoid order effects, the order of the videos shown to the participants was randomized. A practice video was first shown to the participants to familiarize them with the experimental requirements, and allow the researcher to check the quality of participants’ psychophysiological data. To ensure good electrode contact, a period of five minutes was allowed between attaching electrodes to the skin and starting official data collection (Braithwaite et al., 2013). Before the first DPV was played on the computer screen, a baseline level was obtained for each individual. This was measured as the mean activity 10 seconds prior to the first DPV, during which participants were asked to relax and were not exposed to external stimulation. The interval between video clips was set to at least 90 seconds, which allowed responses to return to baseline levels and thus minimize any 'carryover' effect (Fredrickson \& Levenson, 1998). After viewing each DPV, participants were requested to complete a self-report questionnaire regarding their subjective emotional response to the DPV. The digital data collection and timing of the experimental procedures events were controlled by a Dell computer and AcqKnowledge ${ }^{\circledR}$. 
requested to provide their demographic information (gender, age and ethnicity). This was followed by a brief interview, during which each participant was asked to report their viewing experience of the three advertisements, especially those segments that had elicited particular feelings (e.g., happiness or excitement). Participants were then debriefed and thanked for their time. The entire process lasted approximately 1 hour for each individual.

\section{Data analysis}

Consistent with the EMG data analysis guidelines, the mean EMG score was standardized as a proportion of the baseline value (Boxtel, 2001). For skin conductance data, SCR frequency was calculated by counting the number of SCRs during the first 90s of each video (to ensure the consistency among three DPVs), and SCR amplitude was obtained by averaging the SCR amplitude during each DPV period. For moment-to-moment physiological responses, both EMG and SC data were averaged across one-second intervals, eventually yielding 94 time points for the Switzerland DPV and 91 time points for the Hamilton Island DPV. Finally, the moment-to-moment data from 33 participants were aggregated and averaged into one waveform that represented their overall physiological responses to each DPV (Maier, 2009).

Mean facial EMG, SCR frequency, SCR amplitude as well as self-report questionnaire data, were entered into SPSS. ANOVA with repeated measures was used to identify the differences among the three videos and Pearson correlation was used to explore the associations between different data sets. The data were log-transformed if the assumption for repeated-measures ANOVA were violated. The Friedman test was used to identify the differences among the three videos if the assumption for repeated-measures ANOVA was still not satisfied after log transformation. 


\section{Results}

\section{Sample characteristics}

Of the 33 participants, 16 were females and 17 were males. Most (76\%) were aged 18-34, with only 2

participants aged over 45. Twenty-five participants identified themselves as Caucasian, five as Asian, two as Middle Eastern, and one as Black. Most of the participants had not watched the DPVs before with the exception of one participant who had watched the Adelaide DPV. In terms of prior experience with the destinations, thirteen participants had visited Adelaide before, and ten participants had been to Switzerland. Only five had been to Hamilton Island.

\section{Mean self-reported emotional responses}

Figure 1 presents the participants’ self-reported emotional responses to the three DPVs. The Switzerland DPV was judged as more pleasurable $(M=4.06)$ than the Hamilton Island DPV $(M=3.57)$ and the rational Adelaide DPV ( $M=2.24)$. The Friedman test indicated a significant difference among the three DPVs in terms of pleasure levels, $\chi^{2}(2)=39.27, p<.001$. Post hoc analysis with Wilcoxon signed-rank tests was conducted with a Bonferroni correction applied, resulting in lowering the required significance level $(\alpha)$ to .017 rather than .05. The Wilcoxon signed-rank test demonstrated that the Switzerland DPV and the Hamilton Island DPV were both significantly higher than the Adelaide DPV based on viewers' selfreported pleasure levels $(Z=4.95, p<.001 ; Z=4.19, p<.001$, respectively). However, the difference in self-reported pleasure between the Switzerland and Hamilton Island DPVs did not reach the corrected significance level $(Z=2.18, p=0.029)$.

, The Hamilton Island DPV received the highest self-reported ratings of arousal levels $(M=4.03)$, which was followed by the Switzerland DPV $(M=3.63)$ and Adelaide DPV $(M=1.75)$. The Friedman test 
indicated a significant difference in arousal levels in response to the three DPVs, $\chi^{2}(2)=52.22, p<.001$. Post hoc analysis with Wilcoxon signed-rank tests was conducted with a Bonferroni correction applied, resulting in lowering the required significance level $(\alpha)$ to .017 rather than .05 . Both the Hamilton Island and Switzerland DPVs were significantly greater than the Adelaide DPV based on self-reported arousal levels $(Z=5.01, p<.001 ; Z=4.97, p<.001$, respectively). However, the difference in self-reported arousal between the Switzerland and Hamilton Island DPVs did not reach the corrected significance level $(Z=2.24, p=0.025)$.

\section{FIGURE 1 ABOUT HERE}

\section{Mean facial EMG}

As illustrated in Figure 2, participants' physiological pleasure responses to the three DPVs were generally consistent with their self-reported pleasure levels. The Switzerland DPV was most effective in activating zygomatic muscle activity ( $M=655.31 \%)$, followed by the Hamilton Island DPV $(M=370.01 \%)$ and Adelaide DPV ( $M=151.32 \%)$. These three DPVs differed from each other significantly in terms of their

mean EMG, $F(2,64)=14.26, p<.001, \eta^{2}=0.31$. Post hoc tests using the Bonferroni correction revealed that mean EMG responses to the Switzerland DPV were significantly higher than those to the Hamilton Island DPV, which was significantly greater than the Adelaide DPV. This finding suggested that the Switzerland DPV was most effective in terms of evoking positive emotions, which was followed by the Hamilton Island DPV and Adelaide DPV.

\section{FIGURE 2 ABOUT HERE}

\section{Mean SCR frequency and amplitude}

Figure 3a illustrates the participants' physiological arousal responses to the three DPVs as measured by SCR frequency. The results demonstrated that the Hamilton Island DPV $(M=10.21)$ elicited a higher frequency of SCR than the Switzerland DPV ( $M=9.54$ in 90 s) and Adelaide DPV ( $M=6.27$ in 90s). 
Significant differences in the frequency of SCR were found between the three videos, $F(2,64)=38.92, p$ $<.001, \eta^{2}=0.55$. Post hoc tests using the Bonferroni correction revealed that both Hamilton Island and Switzerland DPVs were significantly greater than the Adelaide DPV based on SCR frequency. However, no significant differences in SCR frequency were found between the Hamilton Island and Switzerland DPVs.

Figure 3b shows the mean SCR amplitudes for the three DPVs. Given the difficulty and ambiguity of explaining the results derived from transformed data, this section presents results generated with the original SCR amplitude ${ }^{1}$. Consistent with participants’ self-reported arousal levels and frequency of SCRs, the Hamilton Island DPV $(M=9.00)$ received a higher SCR amplitude score than the Switzerland ( $M=7.95)$ and Adelaide DPVs $(M=7.04)$. Significant differences were found among these three videos in terms of SCR amplitude, $F(2,64)=53.15, p<.001, \eta^{2}=0.62$. Post hoc tests using the Bonferroni correction revealed that the Hamilton Island DPV was significantly greater than the Switzerland DPV which was significantly higher than the Adelaide DPV based on SCR amplitude. This finding indicates that Hamilton Island DPV was most effective in terms of evoking arousal, followed by the Switzerland DPV and Adelaide DPV.

\section{FIGURE 3a and FIGURE 3b ABOUT HERE}

\section{Correlation analysis}

Correlation analysis was performed to assess the relationship between the participants' pleasure levels and arousal levels separately for each of the three DPVs. Using self-report measures, positive relationships were found between pleasure and arousal for all three DPVs (Adelaide $r=0.45, p<0.01$; Switzerland $r=0.41, p<0.05$; and Hamilton Island $r=0.61, p<.001)$. However, no significant correlations were found between pleasure levels and arousal levels when using the physiological measures. These findings suggest

1 The reported results (ANOVA with repeated measure statistics) are based on the transformed data, but the raw means are used to interpret the findings. 
that individuals may have difficulty distinguishing between pleasure and arousal in their self-reported responses. However, this difficulty does not exist when using physiological measures.

In summary, the analysis above revealed that compared with self-report methods, psychophysiological measures are more sensitive discriminators between different tourism commercials as well as between the two dimensions of emotion.

\section{Moment-to-moment physiological responses}

Facial EMG and SC methods are not only able to reflect participants’ overall emotional responses to stimuli, but are also able to capture individuals’ real-time emotional responses. In this section, the capabilities of both facial EMG and SC in displaying individuals’ moment-to-moment emotional responses to destination advertisements are illustrated. In particular, the emotional peaks identified from the real-time facial EMG and SC data are compared and validated by individuals' affective experience reported in the interviews. Consistent with rules for identifying peaks in physiological traces (Biocca, David, \& West, 1994), participants’ real-time facial EMG and skin conductance data were averaged and then standardized across time based on a z-score. Only the z-scores greater than 1.96 were identified as representing significant (peak) time points² ${ }^{2}$ (Biocca et al., 1994).

For simplicity, the potential of real-time facial EMG data is illustrated using participants' continuous physiological pleasure responses to the Switzerland DPV (the highest of the three DPVs in eliciting pleasure). The Switzerland DPV was frequently described as 'funny', 'hilarious', or 'cute' by the participants in the follow-up interview. Correspondingly, participants reported their emotional responses to this video as 'happy'. The usefulness of real-time skin conductance data is illustrated by participants'

\footnotetext{
2 if the $\mathrm{z}$ value is greater than 1.96 or less than -1.96 , it's statistically significant $(\mathrm{p}<.05)$
} 
continuous physiological arousal responses to the Hamilton Island DPV (the most effective of the three DPVs in evoking arousal). In the follow-up interview, participants described the Hamilton Island DPV as 'exciting' and they felt 'excited' or 'nervous'.

\section{Moment-to-moment facial EMG data (Switzerland DPV)}

Figure 4 presents participants’ continuous facial EMG data reflecting their pleasure levels moment to moment (1-second interval), with three significant peaks distributed in the middle and end of the video (labelled as A-C). The following paragraphs discuss these three peaks along with corresponding events that provoked them, and examples of participants’ viewing experience related to these events.

\section{FIGURE 4 ABOUT HERE}

1. Peak A, started from the $33^{\text {rd }}$ second and reached a peak at the $37^{\text {th }}$ second. This peak occurs at the middle of the scene when one of the main characters goes to a lingerie shop and buys his wife a piece of lingerie. This segment was mentioned by 21 out of 33 participants in the follow-up interview. For example:

'It is hilarious when you see a man shopping in a lingerie shop... it was unusual'(R12)

'When they were purchasing in the lingerie it was so funny...you see he was trying to show his wife's picture and check if the outfit can fit his wife...'(R13)

2. Peak B. This peak started from the $75^{\text {th }}$ second and reached a peak at the $77^{\text {th }}$ second. This peak occurs at the end of the segment when one of the characters rolls up his sleeves and shows the girls his new tattoo-a tractor. This segment was mentioned by 11 out of 33 participants in the follow-up interview. For example:

'I like the shot when the man was showing his tattoo to the girl...so funny...also, this frame lasted a long time in the video' (R8).

'The tattoo part was fairly interesting...coz they do not look like the stereotype of people who would get...and it just kind of like something you go on a holiday and do something crazy...'(R24) 
3. Peak $\mathrm{C}$, which appears at the end of the video, started from the $87^{\text {th }}$ second and increased to a peak at the $90^{\text {th }}$ second. Peak $C$ happens in the middle of the scene when the main characters finish their 'day trip' in the city and go back home driving their tractor. This segment was mentioned by 19 out of 33 participants in the follow-up interview. For example:

'I love the end of the video when they were going back home...I mean...At first I did not realize they came from the country until the end of the video... one of them was driving the car and one of them was sleeping, which made me feel relaxed and happy...'(R13).

'I felt happy when they went back with lots of shopping bags...the two guys were driving to the sunset...and they were quite content...I felt relaxed...and I wanna hop on their tractor and join them' (R15).

\section{Moment-to-moment skin conductance level (Hamilton Island DPV)}

Figure 5 shows the waveform across the Hamilton Island DPV, demonstrating participants' real-time skin conductance levels (1 second interval). Overall, participants’ physiological arousal fluctuated at a low level at the start, increased to a peak in the middle and then descended gradually to the end. Thus one significant peak in skin conductance level was identified and labelled A in the graph.

\section{FIGURE 5 ABOUT HERE}

The peak point occurs at the $37^{\text {th }}$ second of the video. However, as can be seen from the waveform, participants' physiological arousal level started to increase from the $20^{\text {th }}$ second, and increased until the peak at the 37th second. The corresponding video segment showed tourists jumping out of the plane one after another, with quite a few high angle shots of the ground from the plane. This segment was mentioned by 24 out of 33 participants in the follow-up interview. For example:

'I felt excited and a bit jealous when they jumped out of the plane...I wanna try some day too but I may not have the nerve to do it...'(R3).

'When they were about to get out of the plane...rolling out...I felt nervous coz that scared me...when 
they were all falling...spinning around...exciting...'(R24).

From these results, it is concluded that major spikes in zygomatic muscle activity are closely related with particular amusing events or scenes in the Switzerland DPV. Likewise, the main peak in skin conductance level is associated with a stimulating scene (jumping out of a plane) in the Hamilton Island DPV. Also, these peak moments were further validated by participants' reports of their viewing experiences of the DPV. Together this demonstrates the usefulness of psychophysiological techniques in tracking dynamic interaction between external stimuli and participants’ emotional responses. 


\section{Discussion and conclusion}

Understanding consumers' emotional responses is key to the success of an advertising appeal, and this is particularly true for tourism, which mainly focuses on the intangible aspects of experience. Based on criticisms of self-report methods in recent tourism literature (Kim \& Fesenmaier, 2015; Li et al., 2015), the primary aim of this methodological study was to explore the usefulness and capabilities of facial EMG and skin conductance methods in measuring emotional responses to destination advertisements. In this section, the major findings of this study will be discussed first. The psychophysiological methods used in this study were found to have some constraints and challenges, as well as benefits. These will be discussed to assist future researchers who are interested in better understanding consumers' emotional responses. This is followed by implications for tourism marketers and limitations of this study.

\section{Major findings of this study}

The results demonstrate that individuals’ self-reported emotional responses to the destination advertisements of this study were consistent with their physiological responses; however, this study provides support for the superiority of physiological methods over self-report, with psychophysiological measures being more sensitive discriminators among destination advertisements compared with selfreport measures. More specifically, significant differences in physiological responses were not only found between emotional advertisements and the non-emotional advertisement, but also between two emotional advertisements. The self-report emotional scales were unable to detect the differences between the two emotional advertisements. This reinforces the limitations of self-report scales in the measurement of advertisement effectiveness as such methods in this case were unable to detect meaningful differences between tourism advertisements that employ emotional appeals. 
Hazlett and Hazlett (1999) indicate that facial EMG outperforms the self-report method in distinguishing different commercials in product categories that are mainly based on utility and instrumentality (e.g., automobile, food or soft drinks). This study extended Hazlett and Hazlett (1999)’s work by using SC measures as well as EMG, and found that both facial EMG and SC are more sensitive discriminators among tourism commercials than self-report measures. In this study, both SCR frequency and SCR amplitude were used to indicate individuals' arousal responses to the destination advertisements. This study reveals that two emotional advertisements significantly differed from each other in SCR amplitude. However, no significant difference in SCR frequency was identified between the two emotional advertisements. One possible interpretation is that these two emotional advertisements contain a similar number of affective frames that are capable of eliciting viewers' arousal (i.e., SCR). Wang and Minor (2008) noted that SCR frequency may reflect both arousal and pleasure levels, and this interaction may affect the ability of SCR frequency to distinguish between the two emotional appeals in this study. Overall, this study demonstrated the usefulness of facial EMG and skin conductance (especially SCR amplitude) measures in distinguishing non-emotional appeals from emotional appeals, as well as in discriminating between two emotional appeals.

This study revealed that psychophysiological measures are able to better distinguish between the two fundamental dimensions of emotion (i.e., pleasure and arousal) than self-report measures. The correlation analysis demonstrates a positive association between participants’ self-reported pleasure and arousal levels in response to the three DPVs. However, no significant associations were identified between participants' physiological pleasure and arousal responses. It is possible that participants may not understand the differences between pleasure and arousal, or may not be able to accurately distinguish between them using a seven-point scale. Psychophysiological methods, on the other hand, are more objective and sensitive measures. Also, psychophysiological responses are not influenced by individuals’ cognitive biases and are less vulnerable to measurement error. The methods this study adopted are 
capable of differentiating the pleasure and arousal dimensions as they are registering different physiological activities on individuals’ bodies.

Apart from accurately capturing individuals' overall emotional responses to tourism advertising stimuli, a further advantage of using physiological measures is the ability to keep track of participants' moment-tomoment responses so that we can understand viewers' watching experience across time. The results indicate that the main peaks in both facial EMG and skin conductance waveforms were closely related with distinct events or segments in the videos. The follow-up interview shed further light on these emotional peaks. This finding is consistent with the recent research conducted by Kim and Fesenmaier (2015) who found that two travelers' EDA patterns were in accordance with their self-reported tour experience. However, while arousal level served as a reflection of how excited the participants were, it is important to note that this method is not able to indicate the valence or direction of their emotional responses. The present study incorporated both SC and facial EMG methods to measure individuals' pleasure and arousal responses to tourism advertising stimuli, which is more comprehensive in understanding individuals’ emotional responses.

\section{Contributions to the field}

The results of this study contribute to the body of literature on tourism by moving beyond the criticisms of self-report measures commonly used in tourism studies and proposing alternative approaches to measuring consumers' real-time continuous responses. Rather than focusing on the final effect of destination advertising, this exploratory study examined alternative ways of measuring consumers’ direct emotional responses to destination advertising. The findings of this study have demonstrated that facial EMG and skin conductance methods are useful in capturing individuals’ overall emotional responses to tourism advertisements. Compared with a self-report method, psychophysiological measures are more 
sensitive discriminators among different tourism commercials and are able to distinguish different dimensions of emotion. More importantly, both facial EMG and skin conductance measures are capable of displaying moment-to-moment responses, which clearly show individuals’ dynamic emotional change. The results of this study do not necessarily imply that self-report questionnaires should be abandoned in tourism research. Psychophysiological measures can be used as complementary methods in tourism marketing research to validate or supplement self-report data. Psychophysiological methods would be particularly useful when the stimuli are associated with sensitive topics or when consumers' subtle responses are not perceptible using self-report methods (Bolls et al., 2001).

\section{Constraints and challenges of psychophysiological methods}

This methodological study has demonstrated that facial EMG and skin conductance measures have great methodological potential for tourism researchers who are interested in better understanding consumers' emotional responses. However, these methods are not without their constraints. In terms of facial EMG, the process of accurately attaching the sensors on participants' facial muscles is time-consuming.

Locating correct recording sites requires practice in advance. Experimenters should be aware that the electrode lead impedance between any two electrode leads should be less than $10 \mathrm{k} \Omega$ (Day, 2002). Thus, the cleanliness of the skin around recording sites is key to the success of the facial EMG data collection (see details in ‘apparatus’ section).

Skin conductance is simpler to measure. However, factors such as the temperature of the laboratory and excessive talking may influence the final results of skin conductance data. Moreover, approximately $10 \%$ of participants are considered to be non-responders (Braithwaite et al., 2013), and their data must be discarded. To achieve good electrode contact, sufficient time (i.e., at least 5 minutes) should be allowed between placing electrodes on the skin and starting official data collection (Braithwaite et al., 2013). We 
conducted this research in a controlled laboratory where the disturbing influences mentioned were reduced to a minimum.

In our case, the data collection session with a single participant typically took 45-65 minutes, which led to difficulty recruiting participants. The data analysis also required time due to the high sampling rate and complexity of the data. The interpretation of physiological data sometimes is dependent on the research paradigm and even the content of the messages (Ravaja, 2004). Nevertheless, in some situations, the value of psychophysiological methods will outweigh the difficulties (Kim et al., 2014). This study provides a new direction for the evaluation of not only tourism promotional material but many other tourism-related stimuli likely to influence tourist behavior, whether this be media reporting, interpretive and educative signage, advertising campaigns or virtual reality type experiences.

\section{Implications for destination tourism marketers}

Given the importance of emotional responses in predicting advertising effectiveness, understanding and accurately measuring consumers' emotional responses is essential for the success of a destination advertisement. The two psychophysiological measures this study examined hold practical implications for tourism advertising communications. First, as more sensitive tools than self-report measures, psychophysiological techniques may be used as alternative methods by destination advertisers in the copy pretesting stage to evaluate the potential effectiveness of advertisements. The usefulness of psychophysiological methods in predicting the success of an advertisement has also been demonstrated in previous research conducted by Hopkins and Fletcher (1994) who showed that an advertisement receiving higher SCR scores had better sales results. Importantly, destination advertisers are able to use psychophysiological techniques to identify the peak moment of an advertisement and to adjust the place where the peak moment occurs. The time of occurrence of the peak point is imperative for the destination 
brand, as having the brand displayed around peak time or at least during a high positive emotion phase could enhance the positive feelings related with the brand, which results in better attitude towards or memory of the brand (Hazlett \& Hazlett, 1999). This was also supported by the peak and end rules indicating that individuals' global evaluations of a past affective episode will be largely influenced by the emotions experienced during peak and end moments (Fredrickson, 2000).

\section{Limitations and future recommendations}

As an exploratory study, this research also has certain limitations. First, the research was conducted in a controlled laboratory rather than a natural consumption environment; therefore participants' reactions to the advertisements may not be the same as their responses at home, or in a shopping center. Future research could be conducted in a more natural environment. However, as Bolls et al. (2001) mentioned, variables present in a more natural setting may influence the effects found in the laboratory environment but will not alter their directions. Also, we used the latest wireless wearable devices manufactured by Biopac $^{\mathrm{TM}}$, which are able to record high quality data while comfortably allowing participants to move in natural indoor environments. Compared with traditional 'wired' psychophysiological equipment used in psychology laboratories, our equipment is small and unobtrusive in nature, which helps to relax participants and reduce stress to minimum levels. Second, the sample size used in this study is small, which would result in low statistical power. However, the significant differences found in this small sample have a high reproducibility with larger samples (Wang \& Sparks, 2015). Third, this study only compared the capabilities of psycho-physiological and self-report methods in measuring emotional responses. It did not include advertising outcome variables such as attitude towards the advertisement or visiting intention. Finally, to avoid participant fatigue and reduce the time commitment required of participants, this study only used two DPVs as emotional stimuli and one DPV as a non-emotional 
stimulus. Future research could extend the advertising appeals and explore the capabilities of other stimuli in evoking consumers’ emotional responses.

Future research could also further incorporate other forms of tourism advertising material such as destination websites, posters, flyers, brochures or photographic images to test the reliability and validity of these psychophysiological techniques. Other psychophysiological techniques such as heart rate and blood pressure are also considered to be potential methods in understanding individuals' emotional responses, and future research could compare different methods in terms of their ability to capture tourists’ emotions. Additionally, variance in physiological responses may also be found among different age groups, ethnic groups, and groups with different levels of familiarity with the video or destination. Future research could enlarge the sample size and examine these potential effects. Future studies could also associate the emotional responses measured by both self-report and psycho-physiological methods with other advertising outcome variables such as attitude towards the advertisement or behavioral intentions, and investigate the predictive power of different measurements. Psychophysiological measures will also allow the objective measurement of tourism consumers' emotional responses in other areas such as consumers' reactions to traveling to disaster stricken destinations (Lim, in press), emotional responses to traditional accommodation compared with new peer-to-peer accommodation sectors (as in the case of Airbnb, Guttentag, 2015), and the influence of affective responses on the tourist’s decision making processes (Lee, Bruwer, \& Song, in press). 


\section{Reference}

Aaker, D. A., \& Stayman, D. M. (1992). Implementing the concept of transformational advertising. Psychology \& marketing, 9(3), 237-253.

Albers, M., D, \& Stafford, M. R. (1999). An international analysis of emotional and rational appeals in services vs goods advertising. Journal of Consumer Marketing, 16(1), 42-57. doi: 10.1108/07363769910250769

Algie, J. A. (2005). A comparison of viewers' cognitive and psychophysiological responses to threat-appeal TV advertisements. In K. U_Ghallach_ir (Eds.), Academy of Marketing: Marketing: Building Business, Shaping Society Conference. Dublin, Ireland: Academy of Marketing.

Ambler, T., Ioannides, A., \& Rose, S. (2000). Brands on the Brain: Neuro-Images of Advertising. Business strategy review, 11(3), 17-30. doi: 10.1111/1467-8616.00144

Bagozzi, R. P., Gopinath, M., \& Nyer, P. U. (1999). The role of emotions in marketing. Journal of the Academy of Marketing Science, 27(2), 184-206.

Bardzell, S., Bardzell, J., \& Pace, T. (2009). Understanding affective interaction: Emotion, engagement, and internet videos. Paper presented at the Affective Computing and Intelligent Interaction and Workshops, 2009. ACII 2009. 3rd International Conference on.

Barrett, L. F., \& Russell, J. A. (1999). The Structure of Current Affect: Controversies and Emerging Consensus. Current Directions in Psychological Science, 8(1), 10-14. doi: 10.2307/20182545

Biocca, F., David, P., \& West, M. (1994). Continuous response measurement (CRM): A computerized tool for research on the cognitive processing of communication messages. In A. Lang (Ed.), Measuring psychological responses to media messages (pp. 15-64). Hillsdale.

Bolls, P. D., Lang, A., \& Potter, R. F. (2001). The effects of message valence and listener arousal on attention, memory, and facial muscular responses to radio advertisements. Communication Research, 28(5), 627-651.

Boucsein, W. (2012). Electrodermal activity. New York: Springer Science+Business Media, LLC.

Boxtel, A. v. (2001). Optimal signal bandwidth for the recording of surface EMG activity of facial, jaw, oral, and neck muscles. Psychophysiology, 38(1), 22-34.

Braithwaite, J. J., Watson, D. G., Jones, R., \& Rowe, M. (2013). A guide for analysing electrodermal activity (EDA) \& skin conductance responses (SCRs) for psychological experiments. Psychophysiology, 49, 1017-1034.

Butterfield, D. W., Deal, K. R., \& Kubursi, A. A. (1998). Measuring the Returns to Tourism Advertising. Journal of Travel Research, 37(1), 12-20. doi: 10.1177/004728759803700102

Cacioppo, J. T., Tassinary, L. G., \& Berntson, G. (2007). Handbook of psychophysiology: Cambridge University Press.

Day, S. (2002). from Bortec Biomedical Ltd, http://www.bortec.ca/pages/resources.htm (accessed 27 September 2011) http://www.bortec.ca/pages/resources.htm

Fredrickson, B., \& Levenson, R. W. (1998). Positive emotions speed recovery from the cardiovascular sequelae of negative emotions. Cognition \& Emotion, 12(2), 191-220.

Fredrickson, B. L. (2000). Extracting meaning from past affective experiences: The importance of peaks, ends, and specific emotions. Cognition \& Emotion, 14(4), 577-606. doi: 10.1080/026999300402808

Fridlund, A. J., \& Cacioppo, J. T. (1986). Guidelines for human electromyographic research. Psychophysiology, 23(5), 567589. doi: 10.1111/j.1469-8986.1986.tb00676.x

Goossens, C. F. (1995). External Information Search: Effects of Tour Brochures with Experiential Information. Journal of Travel \& Tourism Marketing, 3(3), 89-107. doi: 10.1300/J073v03n03_06

Grabe, M. E., Lang, A., Zhou, S., \& Bolls, P. D. (2000). Cognitive Access to Negatively Arousing News: An Experimental Investigation of the Knowledge Gap. Communication Research, 27(1), 3-26. doi: 10.1177/009365000027001001

Guttentag, D. (2015). Airbnb: disruptive innovation and the rise of an informal tourism accommodation sector. Current Issues in Tourism, 18(12), 1192-1217.

Hazlett, R. L., \& Hazlett, S. Y. (1999). Emotional response to television commercials: Facial EMG vs. self-report. Journal of Advertising Research, 39(2), 7-24.

Holbrook, M. B., \& Batra, R. (1987). Assessing the Role of Emotions as Mediators of Consumer Responses to Advertising. Journal of Consumer Research, 14(3), 404-420. doi: 10.1086/209123

Hopkins, R., \& Fletcher, J. E. (1994). Electrodermal measurement: Particularly effective for forecasting message influence on 
sales appeal Measuring psychological responses to media messages (pp. 113-132). Hillsdale, NJ, England: Lawrence Erlbaum Associates, Inc.

Huang, M. H. (2001). The theory of emotions in marketing. Journal of Business and Psychology, 16(2), 239-247. doi: 10.1023/A:1011109200392

Kandampully, J., Mok, C., \& Sparks, B. A. (2001). Service quality management in hospitality, tourism, and leisure. New York: Haworth Hospitality Press.

Kim, D.-Y., Hwang, Y.-H., \& Fesenmaier, D. R. (2005). Modeling tourism advertising effectiveness. Journal of Travel Research, 44(1), 42-49.

Kim, J. J., \& Fesenmaier, D. R. (2015). Measuring Emotions in Real Time Implications for Tourism Experience Design. Journal of Travel Research, 54(4), 1-11.

Kim, S.-B., Kim, D.-Y., \& Bolls, P. (2014). Tourist mental-imagery processing: Attention and arousal. Annals of Tourism Research, 45, 63-76. doi: 10.1016/j.annals.2013.12.005

Kuppens, P., Tuerlinckx, F., Russell, J. A., \& Barrett, L. F. (2013). The relation between valence and arousal in subjective experience. Psychological bulletin, 139(4), 917-940. doi: 10.1037/a0030811

LaBarbera, P. A., \& Tucciarone, J. D. (1995). GSR Reconsidered: A Behavior-Based Approach to Evaluating and Improving the Sales Potency of Advertising. Journal of Advertising Research, 35(5), 33-53.

Lang, P. J. (1980). Behavioral treatment and bio-behavioral assessment: computer applications. In J. B. Sidowski, J. H. Johnson \& T. A. Williams (Eds.), Technology in mental health care delivery systems (pp. 119-1137): Ablex.

LeDoux, J. (1998). The emotional brain: The mysterious underpinnings of emotional life. New York: Simon and Schuster.

Lee, S., Bruwer, J., \& Song, H. (in press). Experiential and involvement effects on the Korean wine tourist's decision-making process. Current Issues in Tourism, 1-17.

Li, S., Scott, N., \& Walters, G. (2015). Current and potential methods for measuring emotion in tourism experiences: a review. Current Issues in Tourism, 18(9), 805-827. doi: 10.1080/13683500.2014.975679

Lim, W. M. (in press). Restoring tourist confidence and travel intentions after disasters: some insights from a rejoinder to a series of unfortunate events in Malaysian tourism. Current Issues in Tourism, 1-5.

Luoh, H.-F., \& Lo, P.-C. (2012). The Effectiveness of Chef Endorsement in Restaurant Print Advertising: Do Respondents' Gender Stereotypes or Genders Matter? Asia Pacific Journal of Tourism Research, 17(4), 416. doi: 10.1080/10941665.2011.627354

Maier, J. r. (2009). Real-time response measurement in the social sciences: methodological perspectives and applications (Vol. Bd. 26.). Frankfurt am Main; New York: Peter Lang.

Mauss, I. B., \& Robinson, M. D. (2009). Measures of emotion: A review. Cognition \& Emotion, 23(2), 209-237. doi: 10.1080/02699930802204677

Micu, A. C., \& Plummer, J. T. (2010). Measurable emotions: how television ads really work : patterns of reactions to commercials can demonstrate advertising effectiveness. Journal of Advertising Research, 50(2), 137-153. doi: 10.2501/S0021849910091300

Morgan, N., \& Pritchard, A. (2000). Advertising in tourism and leisure. Oxford: Butterworth-Heinemann.

Morris, J. D., Woo, C., Geason, J. A., \& Kim, J. (2002). The power of affect: Predicting intention. Journal of Advertising Research, 42(3), 7-18.

Mueller, B. (1987). Reflections of culture: an analysis of Japanese and American advertising appeals. Journal of Advertising Research, 27(3), 51-59.

Ohme, R., Reykowska, D., Wiener, D., \& Choromanska, A. (2009). Analysis of Neurophysiological Reactions to Advertising Stimuli by Means of EEG and Galvanic Skin Response Measures. Journal of Neuroscience, Psychology, and Economics, 2(1), 21-31. doi: 10.1037/a0015462

Partala, T., Surakka, V., \& Vanhala, T. (2006). Real-time estimation of emotional experiences from facial expressions. Interacting with Computers, 18(2), 208-226. doi: http://dx.doi.org/10.1016/j.intcom.2005.05.002

Paulhus, D. L. (2002). Socially desirable responding: The evolution of a construct The role of constructs in psychological and educational measurement (pp. 49-69): L. Erlbaum Associates.

Peacock, J., Purvis, S., \& Hazlett, R. L. (2011). Which broadcast medium better drives engagement? Measuring the powers of radio and television with electromyography and skin-conductance measurements. Journal of Advertising Research, 51(4), 578-585. 
Philipp, M. C., Storrs, K. R., \& Vanman, E. J. (2012). Sociality of facial expressions in immersive virtual environments: a facial EMG study. Biological Psychology, 91(1), 17-21. doi: 10.1016/j.biopsycho.2012.05.008

Plutchik, R. (1980). Emotion: a psychoevolutionary synthesis. New York: Harper \& Row.

Plutchik, R. (1982). A psychoevolutionary theory of emotions. Social Science Information, 21(4-5), 529-553. doi: $10.1177 / 053901882021004003$

Poels, K., \& Dewitte, S. (2006). How to capture the heart? Reviewing 20 years of emotion measurement in advertising. Journal of Advertising Research, 46(1), 18-37. doi: 10.2501/S0021849906060041

Pollay, R. W. (1983). Measuring the cultural values manifest in advertising. Current issues and research in advertising, 6(1), 71-92.

Pratt, S., McCabe, S., Cortes-Jimenez, I., \& Blake, A. (2010). Measuring the effectiveness of destination marketing campaigns: comparative analysis of conversion studies. Journal of Travel Research, 49(2), 179-190. doi: 10.1177/0047287509336471

Ravaja, N. (2004). Contributions of psychophysiology to media research: review and recommendations. Media Psychology, 6(2), 193-235. doi: 10.1207/s1532785xmep0602_4

Ravaja, N., \& Kallinen, K. (2005). Effects of the rate of computer-mediated speech on emotion-related subjective and physiological responses. Behaviour \& Information Technology, 24(5), 365-373. doi: 10.1080/01449290512331335609

Robinson, M. D., Robinson, M. D., \& Clore, G. L. (2002). Episodic and semantic knowledge in emotional self-report: Evidence for two judgment processes. Journal of personality and social psychology, 83(1), 198-215. doi: 10.1037//0022-3514.83.1.198

Ruhanen, L. M., McLennan, C.-L. J., \& Moyle, B. D. (2013). Strategic Issues in the Australian Tourism Industry: A 10-year Analysis of National Strategies and Plans. Asia Pacific Journal of Tourism Research, 18(3), 220-240. doi: 10.1080/10941665.2011.640701

Russell, J. A. (1980). A circumplex model of affect. Journal of personality and social psychology, 39(6), 1161-1178. doi: $10.1037 / \mathrm{h} 0077714$

Russell, J. A., \& Mehrabian, A. (1974). An approach to environmental psychology. Cambridge: M.I.T. Press.

Russell, J. A., \& Pratt, G. (1980). A description of the affective quality attributed to environments. Journal of personality and social psychology, 38(2), 311.

Scherer, K. R. (2009). The dynamic architecture of emotion: Evidence for the component process model. Cognition and Emotion, 23(7), 1307-1351. doi: 10.1080/02699930902928969

Scott, N., Green, C., \& Fairley, S. (2016). Investigation of the use of eye tracking to examine tourism advertising effectiveness. Current Issues in Tourism, 19(7), 634-642. doi: 10.1080/13683500.2014.1003797

Simons, R. F., Detenber, B. H., Roedema, T. M., \& Reiss, J. E. (1999). Emotion processing in three systems: The medium and the message. Psychophysiology, 36(5), 619-627. doi: 10.1111/1469-8986.3650619

Sirgy, M. J. (1991). Value-Expressive versus Utilitarian Advertising Appeals: When and Why to Use Which Appeal. Journal of Advertising, 20(3), 23-33.

Spencer, D. M. (2013). Effectiveness of intra-destination television advertising of tourist attractions and facilities. Journal of Destination Marketing \& Management, 2(3), 155-164. doi: http://dx.doi.org/10.1016/j.jdmm.2013.05.003

Tassinary, L. G., Cacioppo, J. T., \& Vanman, E. J. (2007). The Skeletomotor System: Surface. Handbook of psychophysiology, 267.

Teixeira, T., \& Wedel, M. (2012). Emotion-induced engagement in Internet video advertisements. Journal of Marketing Research, 49(2), 144-159.

Van der Veen, R., \& Song, H. (2014). Impact of the perceived image of celebrity endorsers on tourists' intentions to visit. Journal of Travel Research, 53(2), 211-224.

Walters, G., \& Sparks, B. (2012). The impact of consumption vision and emotion on the tourism consumer's decision behavior. Journal of hospitality \& tourism research, 36(3), 366-389. doi: 10.1177/1096348010390815

Walters, G., Sparks, B., \& Herington, C. (2007). The effectiveness of print advertising stimuli in evoking elaborate consumption visions for potential travelers. Journal of Travel Research, 46(1), 24-34.

Wang, K.-C., Hsieh, A.-T., \& Chen, W.-Y. (2002). Is the tour leader an effective endorser for group package tour brochures? Tourism Management, 23(5), 489-498. doi: http://dx.doi.org/10.1016/S0261-5177(02)00004-3

Wang, Y., \& Sparks, B. A. (2015). An Eye-Tracking Study of Tourism Photo Stimuli: Image Characteristics and Ethnicity. 
Journal of Travel Research, . Published online 29 Dec. doi: 10.1177/0047287514564598

Wang, Y. J., \& Minor, M. S. (2008). Validity, reliability, and applicability of psychophysiological techniques in marketing research. Psychology \& marketing, 25(2), 197-232. doi: 10.1002/mar.20206

Winkielman, P., \& Berridge, K. C. (2004). Unconscious Emotion. Current Directions in Psychological Science, 13(3), 120123. doi: 10.1111/j.0963-7214.2004.00288.x

Winkielman, P., Berridge, K. C., \& Wilbarger, J. L. (2005). Unconscious Affective Reactions to Masked Happy Versus Angry Faces Influence Consumption Behavior and Judgments of Value. Personality and Social Psychology Bulletin, 31(1), 121-135. doi: 10.1177/0146167204271309

Zajonc, R. B. (1980). Feeling and thinking: Preferences need no inferences. AMERICAN PSYCHOLOGIST, 35(2), $151-175$. doi: 10.1037/0003-066X.35.2.151 
Table 1 Three advertisements used in this study

\begin{tabular}{|c|c|c|c|c|c|}
\hline Number & Destination & Duration & Appeal & Content & Source \\
\hline 1 & $\begin{array}{c}\text { Adelaide } \\
\text { (Australia) }\end{array}$ & $90 s^{3}$ & $\begin{array}{c}\text { Non- } \\
\text { emotional }\end{array}$ & $\begin{array}{l}\text { This advertisement features } \\
\text { tourist information and } \\
\text { rational interpretation of } \\
\text { Adelaide, Australia }\end{array}$ & SouthAustralia.com \\
\hline 2 & Switzerland & $94 \mathrm{~s}$ & $\begin{array}{l}\text { Emotional } \\
\text { (Pleasure) }\end{array}$ & $\begin{array}{l}\text { This advertisement } \\
\text { describes two country } \\
\text { men's day trip to a city in } \\
\text { Switzerland }\end{array}$ & Myswitzerland.com \\
\hline 3 & $\begin{array}{l}\text { Hamilton } \\
\text { Island } \\
\text { (Australia) }\end{array}$ & 91s & $\begin{array}{c}\text { Emotional } \\
\text { (Arousal) }\end{array}$ & $\begin{array}{l}\text { This advertisement shows } \\
\text { tourists participating in a } \\
\text { skydiving activity over } \\
\text { Hamilton Island }\end{array}$ & Queensland.com \\
\hline
\end{tabular}


Figure caption:

Figure1 Means of Self-reported emotional responses to the three DPVs (N=33)

Figure 2 Mean Zygomatic muscle activity of the three DPVs (N=33)

Figure 3. SCR freq. and SCR amplitude of the three DPVs

Figure 4 Moment-to-moment facial EMG data (z-score) for the Switzerland DPV (N=33)

Figure 5 Moment-to-moment skin conductance data (z-score) for the Hamilton Island ( $\mathrm{N}=33$ ) 